\title{
KAJIAN KORELASI DIMENSI DAN STANDAR KENYAMANAN BUS RAPID TRANSIT TRANS SIDOARJO TERHADAP LOAD FACTOR
}

\author{
Dwi Muryanto ${ }^{1}$ dan Maulidya Octaviani Bustamin ${ }^{2}$ \\ ${ }^{1}$ Prodi Teknik Sipil, Universitas Dr. Soetomo Surabaya,dwi.muryanto@unitomo.ac.id \\ ${ }^{2}$ Prodi Teknik Sipil, Universitas Dr. Soetomo Surabaya, lidyaocta@unitomo.ac.id
}

\begin{abstract}
ABSTRAK
Bus Rapid Transit (BRT) Trans Sidoarjo merupakan transportasi massal di Kabupaten Sidoarjo yang menerapkan sistem transportasi bis cepat, murah dan ber-AC. Trans Sidoarjo merupakan salah satu bagian dari program penerapan Bus Rapid Transit di Indonesia yang resmi beroperasi pada tanggal 21 September 2015. Dalam pelaksanaan operasionalnya, kinerja pelayanan BRT Trans Sidoarjo kondisi eksisting kurang baik. Salah satu diantaranya nilai load factor tertinggi rata-rata $25 \%$ kurang dari standar Indikator Pelayanan Angkutan Umum yang telah ditetapkan Dirjend. Perhubungan Darat sebesar $70 \%$ sehingga perlu dilakukan evaluasi terhadap penyebab rendahnya nilai load factor. Penelitian ini bertujuan untuk mengevaluasi dimensi BRT Trans Sidoarjo terhadap nilai load factor sehingga diketahui penyebab rendahnya nilai load factor terhadap efektifitas kinerja BRT. Metode penelitian ini menggunakan deskriptif kualitatif dan kuantitatif. Teknik pengumpulan data dilakukan melalui studi literatur untuk data sekunder dan observasi armada BRT untuk data primer. Hasil penelitian ini didapatkan luas netto penumpang duduk sebesar $10,915 \mathrm{M}^{2}$ dan penumpang berdiri sebesar $9,06 \mathrm{M}^{2}$, tingkat kenyamanan penumpang duduk sebesar $0,3638 \mathrm{M}^{2}$ dan penumpang berdiri sebesar $0,1812 \mathrm{M}^{2}$. Hal ini menunjukkan bahwa kapasitas penumpang dan dimensi kendaraan kurang ideal dengan load factor.
\end{abstract}

Kata kunci: bus rapid transit, dimensi, kapasitas, load factor, tingkat kenyamanan

\section{PENDAHULUAN}

Perkembangan suatu kota identik dengan kemudahan adanya fasilitas perkotaan. Fasilitas kota yang dijadikan referensi utama masyarakat adalah adanya aksesibiltas moda transportasi. Transportasi menjadi isu utama dalam research-research nasional dan internasional terutama dari aspek keberlanjutan. Salah satu bentuk implementasi keberlanjutan dari transportasi adalah suatu kota menerapkan adanya kendaraan umum dengan kapasitas besar, misalnya Bus Rapid Transit (BRT). Kabupaten Sidoarjo sudah menerapkan BRT sejak tahun 2015 [2]. BRT di Kabupaten Sidoarjo kurang optimal kinerjanya yang dipengaruhi oleh beberapa faktor salah satunya nilai load factor yang rendah. Hasil penelitian [3] menunjukkan bahwa ketertarikan masyarakat untuk naik BRT Trans Sidoarjo masih rendah terbukti nilai load factor pada jam sibuk tertinggi hanya $43 \%$, dibandingkan nilai load factor berdasarkan standar Dirjend. Perhubungan Darat sebesar 70\% [5]. Tujuan penelitian ini untuk mengevaluasi dimensi BRT Trans Sidoarjo berdasarkan besaran nilai load factor dari penelitian terdahulu sebagai kondisi eksisting BRT saat ini. Prinsip dilakukannya evaluasi ini adalah untuk mendapatkan jawaban atas rendahnya nilai load factor serta efektifitas kinerja BRT Trans Sidoarjo sehingga apa perlu ada kebijakan baru terkait dengan perubahan dimensi BRT. Berdasarkan prinsip dilakukannya evaluasi, maka pentingnya penelitian ini adalah untuk mengevaluasi dimensi BRT Trans Sidoarjo terhadap load factor, sehingga kinerja BRT dapat efektif karena nilai load factor yang tinggi. Hipotesa yang diperoleh adalah efektifitas kinerja BRT berdasarkan dimensi yang berpengaruh terhadap nilai load factor. 


\section{NAROTAMA JURNAL TEKNIK SIPIL \\ e-ISSN: $2460-3430$ \\ VOLUME 2 NOMOR 2 NOVEMBER 2018}

\section{METODOLOGI}

Penelitian ini menggunakan metode diskriptif kuantitatif dan kualitatif dengan parameter yang mengacu pada atribut-atribut yang digunakan dalam pengumpulan data. Penelitian kuantitatif berusaha mencari penjelasan hubungan antara variabel- variabel yang diteliti dengan menggunakan data berupa angka-angka. Data-data yang digunakan adalah data primer (data lapangan) dan data sekunder (data instansional). Pengumpulan data primer dilakukan melalui beberapa tahapan seperti observasi dan pengukuran dimensi BRT, pengamatan fasilitas-fasilitas yang terdapat di BRT, penghitungan jumlah penumpang dan kapasitas kendaraan untuk mendapatkan load factor, survei di dalam BRT untuk mengukur standar kenyamanan. Sedangkan untuk pengumpulan data sekunder dilakukan melalui instansi-instansi terkait seperti Dinas Perhubungan Kabupaten Sidoarjo, Perum DAMRI Unit Bus Kota (UBK) Kota Surabaya. Data-data tersebut juga didukung dengan studi literatur yang sesuai dengan bahasan terutama terkait kinerja pelayanan BRT. Setelah data-data didapatkan kemudian dilakukan rekapitulasi data untuk mendapatkan data yang diperlukan dalam analisis.

\section{HASIL DAN PEMBAHASAN}

\section{- Sistem Operasional}

BRT Trans Sidoarjo dikelola oleh Perum. DAMRI Cabang Surabaya. Untuk garasi dari BRT Trans Sidoarjo sendiri berada di Perum DAMRI Unit Bis Kota Surabaya yang berada di daerah Jagir Wonokromo. Jam operasional dari BRT Trans Sidoarjo dari pukul 05.00 WIB sampai pukul 19.00 WIB. Sistem pemberangkatan bis dimulai dari garasi pada pukul 05.00 WIB menuju Terminal Porong tanpa membawa penumpang. Ada 6 bis langsung menuju Terminal Porong dan hanya 4 bis yang menuju Terminal Purabaya. Bis hanya boleh menaikkan dan menurunkan penumpang di sheltershelter yang tersedia. Pada shelter tertentu akan dilakukan pengecekan/pemerikasaan oleh petugas pengawasan angkutan kota.

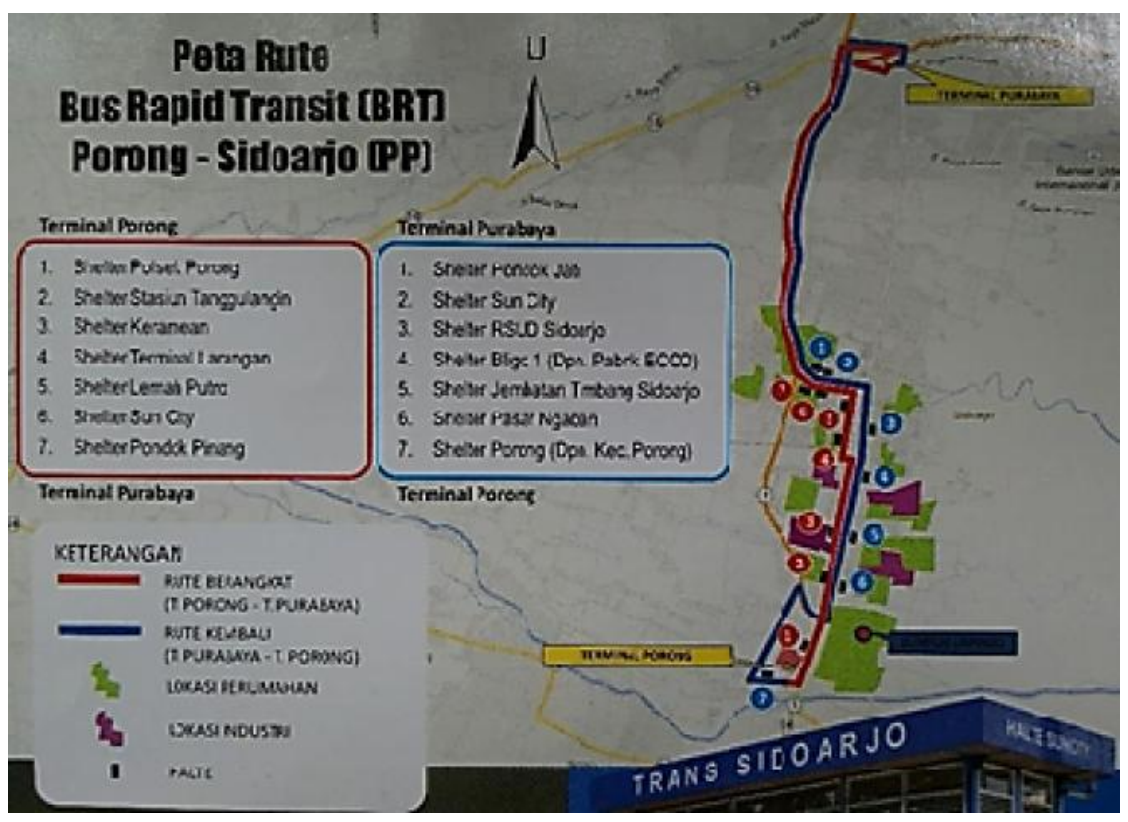

Gambar 1. Rute dan Shelter BRT 


\section{- Kapasitas BRT}

Sumber: Perum DAMRI Cabang Surabaya, 2018

Kapasitas total adalah daya tampung maksimal dari BRT dalam mengangkut penumpang. Untuk itu perlu diketahui jumlah tempat duduk dan berdiri. Berdasarkan hasil survei dan pengamatan diperoleh:

$$
\begin{aligned}
\mathrm{Cv} & =\mathrm{m}+\mathrm{m}^{\prime} \\
& =30+50 \\
& =80 \text { penumpang }
\end{aligned}
$$

dimana: $m=$ jumlah tempat duduk

$\mathrm{m}^{\prime}=$ jumlah tempat berdiri

$$
\begin{aligned}
\mathrm{Co} & =\mathrm{Cv} \times \mathrm{f}_{\max } \times \mathrm{N} \\
\mathrm{f}_{\max } & =3600 / \mathrm{h}_{\min } \\
\mathrm{h}_{\min } & =15 \text { menit } \\
& =900 \text { detik } \\
\mathrm{f}_{\max } & =4 \text { kendaraan/jam } \\
\mathrm{Co} & =80 \times 4 \times 1 \\
& =320 \text { penumpang/jam }
\end{aligned}
$$

Dari hasil perhitungan diatas bisa dilihat bahwa kapasitas total dari BRT $(\mathrm{Cv})$ adalah 80 penumpang per armada sehingga untuk satu jam dengan jumlah armada 4 bis didapat dari hasil analisis maka kapasitas totalnya 320 penumpang setiap armada. Kondisi tempat duduk dan tempat berdiri penumpang ditunjukkan pada Gambar 2.

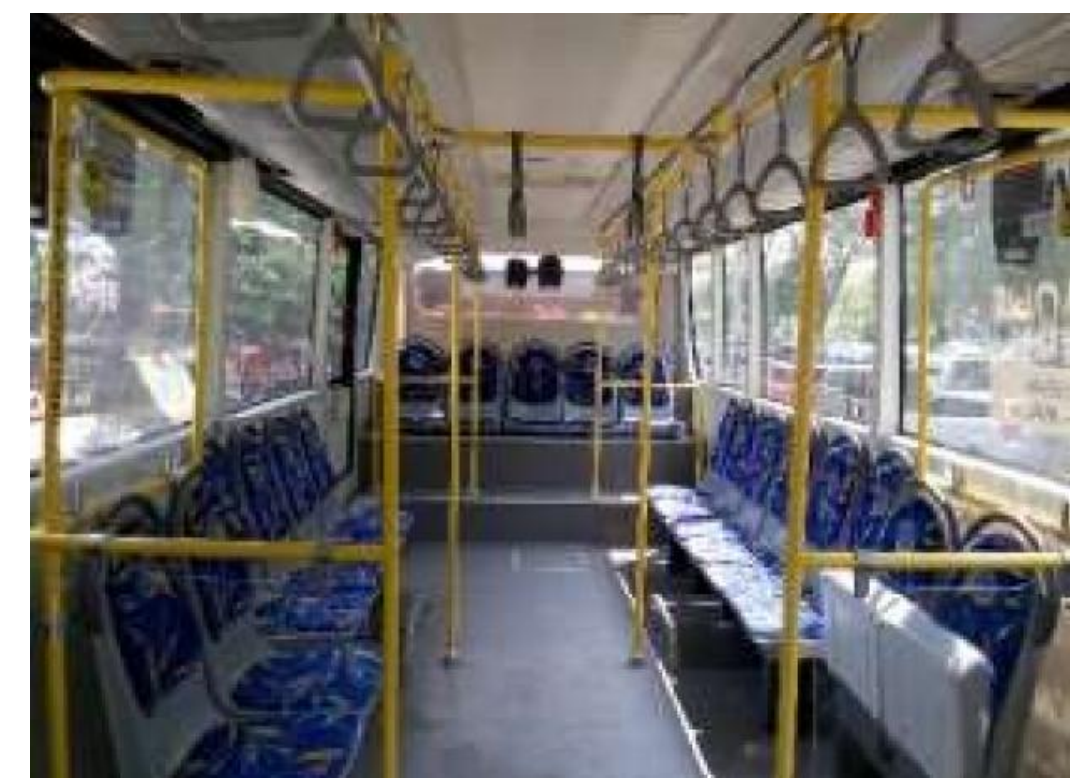

Gambar 2. Kondisi Tempat Duduk dan Berdiri Penumpang Sumber: Survei data primer, 2018

\section{- Analisis Faktor Muat (Load Factor)}

Faktor muat adalah besaran yang menyatakan perbandingan antara jumlah penumpang yang diangkut dengan kapasitas dari kendaraan tersebut. Tujuan dari analisis ini adalah untuk mengetahui rata-rata jumlah penumpang yang diangkut pada trayek tersebut sesuai dengan permintaan yang ada. Menurut Surat Keputusan Dirjend. 
Perhubungan Darat Nomor: SK.687/AJ.206/DRJD/2002 faktor muat bis ideal adalah 70 $\%$ [5].

Dalam pengambilan data naik turun penumpang diambil pada hari Rabu, 7 Maret 2018. Survei dilakukan pada pukul 06.00-18.00 WIB. Surveyor melakukan survei didalam bis, mengikuti bis melewati rute berangkat maupun rute kembali. Surveyor naik bis pertama dari Terminal Porong melewati rute berangkat kemudian setelah sampai di Terminal Purabaya pindah bis yang akan berangkat melewati rute kembali ke Terminal Porong.

Berikut ini load factor rata-rata pada hari Rabu, 7 Maret 2018 untuk Rute Berangkat sebagaimana tabel 1.

Tabel 1. Load Factor Rata-rata BRT Rute Berangkat dari Terminal Porong menuju Terminal Purabaya.

\begin{tabular}{|c|c|c|c|}
\hline NOMOR BRT & $\begin{array}{c}\text { PENUMPANG } \\
\text { DALAM BRT } \\
\text { (Orang) }\end{array}$ & $\begin{array}{c}\text { KAPASITAS BRT } \\
\text { (Penumpang) }\end{array}$ & $\begin{array}{c}\text { LOAD FACTOR } \\
\mathbf{( \% )}\end{array}$ \\
\hline 5677 & 29 & 80 & $36 \%$ \\
\hline 5649 & 24 & 80 & $30 \%$ \\
\hline 5663 & 31 & 80 & $39 \%$ \\
\hline 5672 & 12 & 80 & $15 \%$ \\
\hline 5650 & 14 & 80 & $18 \%$ \\
\hline 5652 & 13 & 80 & $16 \%$ \\
\hline 5662 & 18 & 80 & $23 \%$ \\
\hline 5665 & 16 & 80 & $20 \%$ \\
\hline 5671 & 30 & 80 & $38 \%$ \\
\hline 5664 & 19 & 80 & $24 \%$ \\
\hline 5676 & 16 & 80 & $20 \%$ \\
\hline RATA-RATA & $\mathbf{2 0}$ & $\mathbf{8 0}$ & $\mathbf{2 5 \%}$ \\
\hline
\end{tabular}

Sumber: Hasil pengolahan data primer, 2018

Pada Tabel 1 menunjukkan bahwa nilai load factor BRT tertinggi rata-rata 25\% kurang dari 70\%, tidak memenuhi standar Dirjend. Perhubungan Darat [5].

Berikut ini load factor rata-rata pada hari Rabu, 7 Maret 2018 untuk Rute Kembali sebagaimana tabel 2.

Tabel 2. Load Factor Rata-rata BRT Rute Kembali dari Terminal Purabaya menuju Terminal Porong.

\begin{tabular}{|c|c|c|c|}
\hline NOMOR BRT & $\begin{array}{c}\text { PENUMPANG } \\
\text { DALAM BRT } \\
\text { (Orang) }\end{array}$ & $\begin{array}{c}\text { KAPASITAS BRT } \\
\text { (Penumpang) }\end{array}$ & $\begin{array}{c}\text { LOAD FACTOR } \\
\mathbf{( \% )}\end{array}$ \\
\hline 5655 & 16 & 80 & $20 \%$ \\
\hline 5676 & 14 & 80 & $18 \%$ \\
\hline 5678 & 8 & 80 & $10 \%$ \\
\hline 5677 & 11 & 80 & $14 \%$ \\
\hline 5649 & 13 & 80 & $16 \%$ \\
\hline 5663 & 13 & 80 & $16 \%$ \\
\hline 5672 & 15 & 80 & $19 \%$ \\
\hline 5650 & 11 & 80 & $14 \%$ \\
\hline 5655 & 29 & 80 & $36 \%$ \\
\hline 5676 & 30 & 80 & $38 \%$ \\
\hline 5678 & 35 & 80 & $44 \%$ \\
\hline RATA-RATA & $\mathbf{1 8}$ & $\mathbf{8 0}$ & $\mathbf{2 2 \%}$ \\
\hline
\end{tabular}

Sumber: Hasil pengolahan data primer, 2018 


\section{NAROTAMA JURNAL TEKNIK SIPIL \\ e-ISSN: $2460-3430$ \\ VOLUME 2 NOMOR 2 NOVEMBER 2018}

Pada Tabel 2 menunjukkan bahwa nilai load factor BRT tertinggi rata-rata kurang dari 70\%, tidak memenuhi standar Dirjend. Perhubungan Darat [5].

\section{- Standar Kenyamanan}

Standar kenyamanan bisa dilihat dari area yang dialokasikan untuk tempat duduk dan tempat berdiri. Jumlah tempat duduk ada 30 termasuk dengan 6 kursi prioritas dan jumlah hand stand/tempat berdiri ada 50. Di dalam bis juga terdapat 1 tempat khusus untuk yang mengunakan kursi roda terlihat pada Gambar 3.

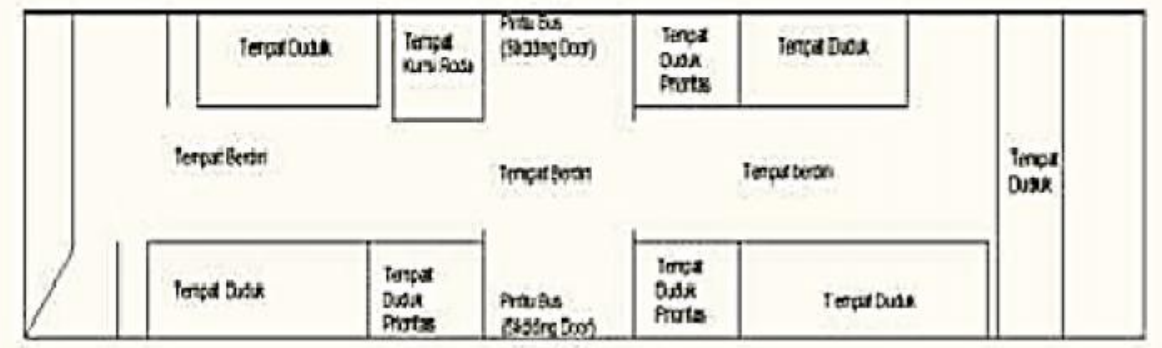

Gambar 3. Denah BRT Trans Sidoarjo

Sumber: Survei data primer, 2018

Untuk menghitung tingkat kenyamanan dengan menggunakan rumus sebagai berikut:

Jumlah tempat duduk $(\mathrm{m})=30$ kursi

Luas netto tempat untuk penumpang duduk $(\mathrm{Ad})$ :

$\mathrm{Ad}=(0,7 \times 1,8)+(0,7 \times 2,2)+(0,7 \times 1,8)+(0,7 \times 2,5)+(3 \times 0,7 \times 1,05)+(0,7 \times 2,2)$

$$
=10,915 \mathrm{~m}^{2}
$$

Tingkat Kenyamanan Tempat Duduk $(\rho)$ :

$$
\begin{aligned}
\rho & =\mathrm{Ad} / \mathrm{m} \\
& =10,915 \mathrm{~m}^{2} / 30 \\
& =\mathbf{0 , 3 6 3 8} \mathbf{~ m}^{\mathbf{2}}
\end{aligned}
$$

Luas netto tempat untuk penumpang berdiri $(\mathrm{Ab})$ :

$$
\begin{aligned}
\mathrm{Ab} & =(0,8 \times 2,85)+(1,5 \times 2,2)+(0,8 \times 3,55) \\
& =\mathbf{9 , 0 6} \mathbf{~ m}^{\mathbf{2}}
\end{aligned}
$$

Jumlah pegangan tempat berdiri $\left(\mathrm{m}^{\prime}\right)=50$

Tingkat Kenyamanan Tempat Berdiri $(\sigma)$ :

$$
\begin{aligned}
\sigma & =\mathrm{Ab} / \mathrm{m} \\
& =9,06 / 50 \\
& =\mathbf{0 , 1 8 1 2} \mathbf{~ m}^{\mathbf{2}}
\end{aligned}
$$

Rasio jumlah tempat duduk dan tempat berdiri:

$$
\begin{aligned}
\text { Rasio } & =\mathrm{m} / \mathrm{m} \\
& =30 / 50 \\
& =\mathbf{0 , 6}
\end{aligned}
$$

Berdasarkan hasil perhitungan tingkat kenyamanan penumpang memenuhi standar, yaitu luasan untuk penumpang yang duduk sebesar $0,3638 \mathrm{~m}^{2}$ dengan standar $\left(0,3-0,55 \mathrm{~m}^{2}\right)$ dan luasan untuk penumpang yang berdiri sebesar $0,1812 \mathrm{~m}^{2}$ dengan 
standar $\left(0,15-0,25 \mathrm{~m}^{2}\right)$. Maka BRT Trans Sidoarjo memenuhi standar kenyamanan yang ada.

\section{- Besar Arus Penumpang}

Arus penumpang BRT dipengaruhi oleh frekuensi kendaraan, kapasitas kendaraan dan load factor. Perhitungan besarnya arus penumpang adalah dengan memasukkan semua nilai faktor-faktornya kedalam rumus:

$$
\mathbf{Q}=\mathbf{F} \times \mathbf{C v} \times \mathbf{L F}
$$

Dimana:

$\mathrm{Q}=$ arus penumpang $(\mathrm{pnp} / \mathrm{jam})$

$\mathrm{F}=$ frekuensi kendaraan (kend/jam)

$\mathrm{Cv}=$ kapasitas kendaraan (orang)

$\mathrm{LF}=$ load factor

- Contoh perhitungan arus penumpang jam puncak pagi (pukul 06.00-07.00 Wib).

Frekuensi BRT : 4 kend/jam

Kapasitas BRT : 80 penumpang

Load Factor : 0,44

Arus penumpang $(\mathrm{Q})=4 \times 80 \times 0,44=212$ penumpang/jam

Hal ini berarti bahwa arus penumpang pada jam puncak pagi sebesar 212 penumpang/jam. Perhitungan untuk arus penumpang rata-rata per hari adalah sebagai berikut:

Frekuensi rata-rata BRT : 4 kend/jam

Kapasitas BRT : 80 penumpang

Load factor rata-rata : $: 25 \%$

Waktu operasional BRT : 14 jam per hari

$\mathrm{Q}=4 \times 80 \times 0,25=80$ penumpang/jam atau 960 penumpang/hari

Berdasarkan analisis diatas diketahui bahwa arus penumpang dengan kapasitas BRT tidak ideal dengan Pedoman Teknis Penyelenggaraan Angkutan Penumpang Umum Di Wilayah Perkotaan Dalam Trayek Tetap dan Teratur [5] sebagaimana Tabel 3 .

Tabel 3. Kapasitas Kendaraan Angkutan Umum

\begin{tabular}{|c|c|c|c|c|}
\hline \multirow[b]{2}{*}{ Jenis Anglutan } & \multicolumn{3}{|c|}{ Kapasitas Kendaraan } & \multirow{2}{*}{$\begin{array}{c}\text { Kapasitax } \\
\text { Rexumpang } \\
\text { ReshariKen daraan }\end{array}$} \\
\hline & Duduk & Berdifi & Total & \\
\hline Mobil penumpang ymum & 8 & - & 8 & $250-300$ \\
\hline Bus Kecil & 1 & - & 19 & $300-400$ \\
\hline Bus Sedang & 2 & 1 & 30 & $500-600$ \\
\hline Bus besax lantai tunggel & 4 & 3 & 79 & $1000-1200$ \\
\hline Bus besar lantai ganda & 8 & 3 & 120 & $1500-1800$ \\
\hline
\end{tabular}

Sumber: Pedoman Teknis Penyelenggaraan Angkutan Penumpang Umum Di Wilayah Perkotaan Dalam Trayek Tetap dan Teratur 


\section{KESIMPULAN DAN SARAN}

\section{Kesimpulan}

1. Load Factor tertinggi pada jam sibuk adalah $44 \%$ dan load factor rata-rata $25 \%$, tidak sesuai dengan standar Dirjend. Perhubungan Darat yang menetapkan nilai load factor $70 \%$

2. Dimensi dan kapasitas BRT tidak ideal dengan besar arus penumpang sehingga tidak memenuhi standar Pedoman Teknis Penyelenggaraan Angkutan Penumpang Umum Di Wilayah Perkotaan Dalam Trayek Tetap dan Teratur.

3. Standar kenyamanan penumpang duduk dan berdiri masih ideal, dimana luasan untuk penumpang yang duduk sebesar $0,3638 \mathrm{~m}^{2}$ dengan standar $\left(0,3-0,55 \mathrm{~m}^{2}\right)$ dan luasan untuk penumpang yang berdiri sebesar $0,1812 \mathrm{~m}^{2}$ dengan standar $\left(0,15-0,25 \mathrm{~m}^{2}\right)$.

\section{Saran}

1. Faktor muat yang rendah meningkatkan kenyamanan penumpang, tetapi berimplikasi pada biaya operasional kendaraan sehingga perlu dilakukan penelitian terkait BOK BRT Trans Sidoarjo.

2. Dimensi BRT perlu disesuaikan dengan besar arus penumpang supaya ideal dengan kapasitas kendaraan dan nilai load factor

\section{DAFTAR PUSTAKA}

1. Herbowo, N. 2012. Studi Persepsi Pengguna TransJakarta Pada Koridor II (Pulogadung-Harmoni). Jurnal Perencanaan Wilayah dan Kota. 23 (1): 37-50.

2. Muryanto, D., Santosa, R. 2016. Kajian Operasional Bus Rapid Transit (BRT) Koridor Utara Selatan Kabupaten Sidoarjo. Prosiding Temu Ilmiah Ikatan Peneliti Lingkungan Binaan Indonesia. 27 Oktober 2016, ITN, Malang. Hal. 27-30.

3. Pungut, A., Suning. 2016. Keberlanjutan Operasional BRT TransSidoarjo Terhadap Aksesibilitas Antar CBD. Prosiding Temu Ilmiah Ikatan Peneliti Lingkungan Binaan Indonesia. 30 November 2016, ITN, Malang. Hal. 31-34.

4. Suning, Pungut, A. 2016. Evaluasi Kesesuaian Jalur Trayek BRT Trans Sidoarjo Terhadap Pengembangan Antar CBD. Prosiding Seminar Nasional Teknologi Informasi, Komunikasi, dan Industri (SNTIKI). 9 November 2016, Pekanbaru, Riau. Hal. 232-237

\section{Peraturan Perundang-undangan:}

5. Keputusan Direktur Jenderal Perhubungan Darat No. SK.687/AJ.206/DRJD/2002 Tahun 2002 tentang Pedoman Teknis Penyelenggaraan Angkutan Umum Di Wilayah Perkotaan Dalam Trayek Tetap Dan Teratur.

6. Keputusan Menteri Perhubungan No. KM 35 Tahun 2003 tentang Penyelenggaraan Angkutan Orang Dengan Kendaraan Umum. 